\title{
Differential Brain Activity in Alcoholics and Social Drinkers to Alcohol Cues: Relationship to Craving
}

\author{
Hugh Myrick*,1,2,3, Raymond F Anton', Xingbao Li' ${ }^{1,3}$, Scott Henderson ${ }^{1,2,3}$, David Drobes', Konstantin \\ Voronin' and Mark S George ${ }^{1,2,3}$
}

'Department of Psychiatry and Behavioral Sciences, Alcohol Research Center, Medical University of South Carolina, 67 President Street, Charleston, SC 29425, USA; ${ }^{2}$ Ralph H. Johnson Department of Veterans Affairs Medical Center, Research and Development Senvice, 109 Bee Street, Charleston, SC 2940I, USA; ${ }^{3}$ MUSC Center for Advanced Imaging Research (CAIR), USA

\begin{abstract}
Using $\mathrm{PMRI}$, our group previously found that after a sip of alcohol and exposure to alcohol beverage pictures, alcoholics compared to social drinkers had increased differential brain activity in the prefrontal cortex and anterior thalamus. This study extends this earlier work with several improvements including imaging the entire brain (rather than the anterior half previously) and recording craving, while the subjects viewed images within the scanner. In a Philips $1.5 \mathrm{~T}$ MRI scanner, 10 nontreatment-seeking alcoholics and 10 age-matched healthy social drinkers were given a sip of alcohol before viewing a 12 min randomized presentation of pictures of alcoholic beverages, nonalcoholic beverages, and two different visual control tasks. During picture presentation, changes in regional brain activity were measured in 15 transverse T2*-weighted blood oxygen level dependent slices. Subjects rated their urge to drink after each picture sequence. After a sip of alcohol, while viewing alcohol cues compared to viewing other beverage cues, the alcoholics, but not social drinkers, reported higher craving ratings and had increased activity in the prefrontal cortex and anterior limbic regions. Brain activity in the left nucleus accumbens, anterior cingulate, and left orbitofrontal cortex significantly correlated with subjective craving ratings in alcohol subjects but not in control subjects. This study suggests, as did our earlier study, that alcoholics and not social drinkers, when exposed to alcohol cues, have increased brain activity in areas that reportedly subserve craving for other addictive substances.

Neuropsychopharmacology (2004) 29, 393-402, advance online publication, 12 December 2003; doi: I 0.1038/s..npp. I 300295
\end{abstract}

Keywords: neuroimaging; alcoholism; craving

\section{INTRODUCTION}

Craving for substances of abuse is important in perpetuating addictive behavior. Craving can be considered a multidimensional phenomenon associated with a strong desire to consume a reinforcing/rewarding drug. Exposure to environmental stimuli associated with the particular rewarding drug can trigger these thoughts or 'urges' that often lead to relapse. Improved understanding of the brain regions involved in craving would increase our knowledge of the neuronal substrates of craving, and also represent potential targets for treatment interventions.

Neuroimaging techniques such as fMRI and PET have begun to shed light on the brain regions involved in craving. A number of investigators have shown that viewing cocaine images are associated with specific relative increases in regional brain activity (Breiter et al, 1997; Childress et al, 1999; Grant et al, 1996). These investigators have generally

\footnotetext{
*Correspondence: Dr H Myrick, MUSC, Institute of Psychiatry 4N, 67 President St, Charleston, SC 29425, USA, Tel: + I 843792 2727, fax: + I 843792 7353, E-mail: myrickh@musc.edu

Received 12 December 2002; revised 28 May 2003; accepted 24 July 2003

Online publication: 30 July 2003 at http://www.acnp.org/citations/ Npp07300302455/default.pdf
}

found activation by cocaine cues in brain regions thought to be involved in reward (nucleus accumbens), arousal (medial temporal lobes, cingulate gyrus), memory (dorsal lateral prefrontal cortex), and sensory integration (thalamus).

Relatively, few studies have assessed brain changes associated with craving for alcohol. Modell and Mountz (1995), utilizing SPECT imaging, reported increased blood flow in the right caudate nucleus during craving induction in alcoholics. Hommer et al (1997), utilizing PET imaging, used a challenge of $m$-chlorophenylpiperazine to induce craving in alcohol subjects and controls. While no subjective craving was elicited, activations were found in the cerebellum, posterior cingulate, and thalamus in the alcohol group.

Recently, our group used fMRI to evaluate regional brain activity changes in alcoholics and social drinkers during alcohol cue stimulation (George et al, 2001). The results from this study revealed that alcoholics, as a group, had greater relative increases in brain activation in the anterior thalamus and left dorsal lateral prefrontal cortex during alcohol-specific cues, while the social drinkers did not have any alcohol cue-specific brain activation. Furthermore, this work demonstrated that taste and visual cues could induce brain activation in alcoholics within the MRI environment. Two subsequent studies have utilized fMRI with visual 
(Braus et al, 2001) or olfactory (Schneider et al, 2001) cues. These studies found activation of the putamen as well as the subcortical-limbic region and cerebellum, respectively.

In the current study, we sought to replicate our earlier results, while also employing several design improvements. The main modifications from the original work include (1) the use of full visual field goggles within the scanner (instead of prism glasses to view the slides at one's feet); (2) the acquisition of real-time 'craving' data within the scanner; and (3) the acquisition of whole-brain images (made possible by more powerful MRI gradients).

\section{SUBJECTS AND METHODS}

\section{Subjects}

In total, 12 nontreatment-seeking adult alcoholics as well as 17 matched healthy social drinking controls $(<14$ drinks/ week) were recruited. Subjects were recruited through advertisements in the community and signed written informed consent approved by the Medical University of South Carolina Institutional Review Board. Two alcohol subjects and seven social drinkers had unusable MRI data due to excessive movement during the scanning session that was not able to be corrected $(>1 \mathrm{~mm})$. Therefore, 10 alcohol subjects (two females) and 10 control subjects (two females) were used for final analysis. The alcohol subjects had a mean age of $33.6(\mathrm{SD}=11.51)$, while control subjects had a mean age of $33.1 \quad(S D=10.44)$. There were no significant differences in age, gender, race, or education between the groups (Table 1). All alcohol subjects met DSM-IV criteria for alcohol dependence, including meeting criteria for using more alcohol than anticipated or unable to cut down or stop drinking. Exclusion criteria included DSM-IV criteria for any other substance dependence disorder (excluding caffeine) or Axis I psychiatric disorder. All subjects were nonsmokers. Subjects refrained from alcohol use for $24 \mathrm{~h}$ prior to the scanning procedure. A breathalyzer and urine drug screen were performed immediately prior to the imaging session. In addition, subjects were assessed for alcohol withdrawal symptoms using the Clinical Institute Withdrawal Assessment for Alcohol-revised (CIWA-Ar) (Sullivan et al, 1989), immediately prior to the scanning session.

\section{Procedures}

On the day of the imaging session, subjects completed a battery of assessments including the Obsessive Compulsive Drinking Scale (OCDS) (Anton et al, 1996), the CIWA-Ar, a timeline followback for drinking data (TLFB) (Sobell et al, 1988), and a series of visual analog scales that assessed a variety of alcohol craving indices such as the amount of craving and frequency of craving. All scans took place around noon on each scanning day to minimize time of day confounds.

The cue-induced MRI scanning procedure was similar to our original study (George et al, 2001). Briefly, as depicted in Figure 1, alcohol and nonalcohol beverage picture cues were selected primarily from the Normative Appetitive Picture System (NAPS) (Breiner et al, 1995) but supplemented to avoid repeating the same stimuli during the scanning sequence. Visual control pictures match the alcohol cues in color and hue but lack any object recognition. A 12-min sequence for stimulus presentation was created consisting of six, 120-s, epochs. Each epoch contains four 24-s blocks (one block each of alcohol, nonalcohol beverage and visual control pictures, and crosshair). Each 24-s block is made up of five individual pictures, each displayed for approximately $4.8 \mathrm{~s}$. The alcohol blocks
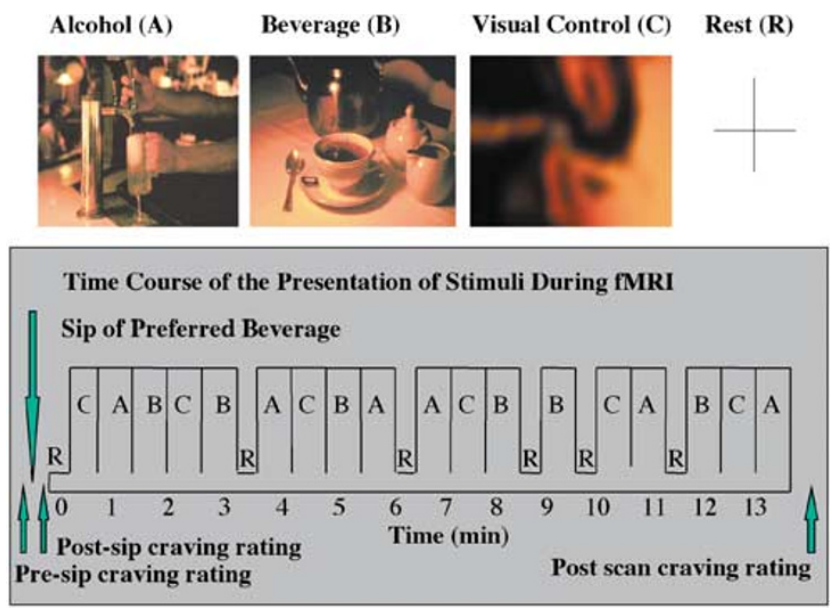

Figure I Representative stimuli and a diagram of the alcohol-induction paradigm.

Table I Subject Demographics and Baseline Alcohol Use Parameters

\begin{tabular}{lccl}
\hline & Alcohol $(\boldsymbol{n}=\mathbf{I 0})$ & Control $(\boldsymbol{n}=\mathbf{1 0})$ & Statistics \\
\hline Age (years) & $33.60 \pm 11.51$ & $33.10 \pm 10.44$ & Nonsignificant \\
Education & $15.15 \pm 1.73$ & $16.30 \pm 1.57$ & Nonsignificant \\
Gender (\% Male) & 80 & 80 & Nonsignificant \\
Race (\% Caucasian) & 70 & 100 & Nonsignificant \\
Drinks in past month & $164.39 \pm 99.54$ & $11.93 \pm 10.34$ & $t=4.82, \mathrm{df}=\mid 8, p<0.01$ \\
Drinks/drinking day & $8.17 \pm 4.14$ & $2.18 \pm 1.34$ & $t=4.35, \mathrm{df}=18, p<0.01$ \\
Amount of craving & $42.60 \pm 22.17$ & $8.30 \pm 12.02$ & $t=4.30, \mathrm{df}=18, p<0.01$ \\
Frequency of craving & $35.90 \pm 23.79$ & $8.30 \pm 12.02$ & $t=3.28, \mathrm{df}=18, p<0.01$ \\
OCDS & $9.80 \pm 4.78$ & $2.6 \pm 1.84$ & $t=4.77, \mathrm{df}=18, p<0.01$ \\
\hline
\end{tabular}


are specific to a beverage type (beer, wine, or liquor), with two blocks per type. After each block, subjects had $6 \mathrm{~s}$ to self-rate their craving in real-time on a visual analog scale as described below. Since stimulus-induced brain activity is small relative to the natural variability in brain activity, stimuli need to be presented multiple times to validly measure a specific activity signal. In order to control for time and order effects across subjects, the order of the individual pictures, the blocks within the epoch, and the epochs were all randomly presented.

In addition, a $10-\mathrm{min}$ relaxation script was created from the International Affective Picture System (CSEA-NIMH, 1995), consisting of 20 natural scenic pictures, each displayed for $30 \mathrm{~s}$. These pictures were displayed during MRI scanning setup, tuning sequences, volumetric, and structural scans. The pictorial scripts were created and displayed in Superlab (Phoenix, AZ) on a Power Macintosh. The computer was connected to MRI-compatible nonferromagnetic goggles, and a track-ball in the scanner bore.

\section{MRI Image Acquisition}

Subjects wore earplugs and head movement was restricted using foam cushions surrounding the head. They were fitted with 3-D MR compatible goggles (Resonance Technology, Northridge, CA) and had a small plastic tube placed in the corner of their mouth to provide a subsequent sip of alcohol (one ounce of beer). A trackball connected to a Macintosh was placed in their dominant hand to allow a real-time ability to measure changes in craving on a visual analog scale. The visual analog scale consisted of a $100 \mathrm{~mm}$ scale in which the subject could rate their 'urge to consume alcohol' from 'not at all' to 'maximum possible'. Prior to entering the scanner, the subjects were trained to move the track-ball along the analog scale and clicking the appropriate position with the mouse.

MRI scans were performed in a Philips 1.5 T MR scanner. An initial high-resolution (142 slice $1 \mathrm{~mm}$ thick) sagittal T1weighted scan was acquired for later volumetric and coregistration analysis, and to ensure there were no large infarcts or tumors. A structural scan was then taken consisting of 15 coplanar transverse slices ( $8 \mathrm{~mm}$ thick/ $0 \mathrm{~mm}$ gap) covering the entire brain and positioned using a sagittal scout image. Following another manual tuning for echo-planar imaging, the cue-induction paradigm was performed while also acquiring blood oxygen level dependent (BOLD) weighted transverse scans in the exact plane as before using a gradient echo, echo-planar (EPI) fMRI sequence (tip angle $=90^{\circ}, \mathrm{TE}=45.0 \mathrm{~ms}, \mathrm{TR}=3.176 \mathrm{~ms}$, $\mathrm{FOV}=256,158-\mathrm{mm}$ thick slices, gap $=0.0 \mathrm{~mm}$, with frequency selective fat suppression). Immediately prior to acquiring the BOLD images, the subjects were given a sip (one ounce of beer) through the small plastic tube in their mouth.

\section{Data Analysis}

Subject demographics and rating scales were compared between groups using $t$-tests and repeated measures ANOVA.

MR images were changed into ANALYZE format and then further processed on Sun workstations (Sun Microsystems,
Palo Alto, CA). Scans were checked using MEDx3.3 (Sensor Systems Inc., Sterling, VA) for movement within runs. Volumes were then motion corrected to less than $1 \times 1 \times 1 \mathrm{~mm}^{3}$ in all planes using Automatic Image Registration (Woods et al, 1992). After motion correction, all data sets were required to have less than 1-mm movement in all planes. There was no difference in average overall movement in the $x, y$, or $z$ direction after motion correction in the alcoholics as compared to controls ( $x$ direction: alcoholics $x=0.11 \mathrm{~mm}$, controls $x=0.14 \mathrm{~mm}(t=-0.63$, $\mathrm{df}=18, p=0.53) ; y$ direction: alcoholics $y=0.30 \mathrm{~mm}$, control $y=0.37 \mathrm{~mm}(t=-0.76, \mathrm{df}=18, p=0.46) ; z$ direction: alcoholics $z=0.60 \mathrm{~mm}$, controls $z=0.66 \mathrm{~mm}$ $(t=-0.32, \mathrm{df}=18, p=0.75))$.

Using the Statistical Parametric Mapping (SPM) 96 module in MEDx3.3, the data were temporally filtered using a high-pass filter removing fMRI intensity patterns greater than twice the cycle length's period (254 s), and transformed into Talairach space (Talairach and Tournoux, 1988) with output voxel dimensions $4 \times 4 \times 4 \mathrm{~mm}^{3}$, and spatially smoothed using an $8 \times 8 \times 8 \mathrm{~mm}^{3}$ Gaussian kernel.

Individual $f M R I$ data analysis. Individual $z$ maps were generated using SPM96 with a delayed boxcar model, temporal smoothing, and an uncorrected $\mathrm{F}$ threshold of 0.999. There is a problem with MEDx3.3 where for any comparison it only computes positive $z$-values, and discards all zero or negative differences. To get around this problem and be able to examine increases as well as decreases for a given comparison, we used the image calculator in MEDx3.3 to combine the two subtraction $z$ maps for each comparison of interest after converting the sign of the initially negative values (ie, for comparison, alcohol $v s$ beverage, subtractions of alcohol minus beverage (positive values) \& beverage minus alcohol (positive values, then converted to negative values) were combined to give one $z$ map with the full range of differences between the conditions). The resulting statistical map had both positive and negative $z$-values. The individual subject's fMRI data were analyzed to generate unthresholded $z$ maps for alcohol minus beverage and beverage minus alcohol, alcohol minus control and control minus alcohol, beverage minus control and control minus beverage, control minus rest and rest minus control. The individual $z$ maps were then combined for the group analysis.

Within-group fMRI data analysis. Each subject's unthresholded $z$ maps were combined based on comparisons of interest (Alcohol minus Beverage \& Beverage minus Alcohol, Alcohol minus Control \& Control minus Alcohol, Beverage minus Control \& Control minus Beverage, Control minus Rest \& Rest minus Control). The combined group (either Alcoholics or Social Drinkers) $z$ maps were thresholded using $z \geqslant 1.645$ and cluster statistical weight (spatial extent threshold) of corrected $p<0.05$. Local maxima for these group cluster maps were then determined.

Between-group fMRI data analysis. The Alcohol minus Beverage condition unthresholded $z$ maps for both the Alcohol and Social Drinkers were compared using MEDx3.3. $z$ maps were thresholded using $z \geqslant 1.645$ and a 
cluster statistical weight (spatial extent threshold) of $p<0.05$.

Correlation analysis. Within-group correlations between subjective craving rating and brain activity measures were performed in MEDx3.3 on the functional data for the alcohol and control groups using brain activity data measured during the alcohol condition alone. A text file readable in MEDx was made from the visual analog craving rating data obtained, while the subjects were in the scanner. A correlation model was then constructed with each time point in the alcohol condition matching the craving rating for that block of alcohol pictures. The images (motion corrected, temporal filtered, smoothed, and normalized into Talairach space) were then loaded for the correlation. After a temporal auto-correlation correction was applied with a hemodynamic lag $(2 \times \mathrm{TR}=6.3)$, each subject's correlation $z$ map was obtained. A random effects model was used to generate the group correlation $z$ map. The group $z$ maps were thresholded using $z \geqslant 1.96$ and cluster statistical weight (spatial extent threshold) of $p<0.05$. The local maxima for these group cluster maps were then identified. To determine the specificity of the findings, a similar correlation was conducted using the craving rating data obtained during the beverage condition.

\section{RESULTS}

\section{Demographics and Subjective Ratings}

As can be seen in Table 1, and as expected, there were significant baseline differences in alcohol use parameters between the alcoholic and social drinker groups. The alcoholic group consumed more drinks in the 30 days prior to study initiation $(t=4.82, \mathrm{df}=18, p<0.01)$ and had more drinks per drinking day $(t=4.35, \mathrm{df}=18, p<0.01)$ than the social drinkers. There was no evidence of alcohol withdrawal symptoms in either group as the CIWA-Ar scores were zero. In addition, urine drug screens obtained prior to the subjects entering the scanner were negative.

There were several indices of a difference in craving between alcohol subjects and controls. At baseline, the alcoholic group reported an increased amount of craving $(t=4.30, \mathrm{df}=18, p<0.01)$, frequency of craving $(t=3.28$, $\mathrm{df}=18, p<0.01)$, and a higher OCDS score $(t=4.77$, $\mathrm{df}=18, p<0.01)$ as compared to the social drinking control group. Alcohol subjects also had significantly higher preand postsip alcohol craving while in the scanner. As can be seen in Figure 2, there were significant differences between alcohol subjects and control subjects with regards to the craving ratings during visual presentation within the scanner $(\mathrm{F}=10.712, \mathrm{df}=1, p=0.004)$. The alcohol subject's 'urge to consume alcohol' was significantly higher for the alcohol pictures, beverage pictures, control pictures, and rest pictures as compared to control subjects. Within the alcoholic group, there were higher ratings of craving during viewing of alcohol pictures $(\mathrm{F}=10.283, \mathrm{df}=1, p=0.005)$.

\section{Comparison of Alcohol Cues with Beverage Cues}

The brain areas that significantly activated within each group during the comparison of alcohol cues and beverage

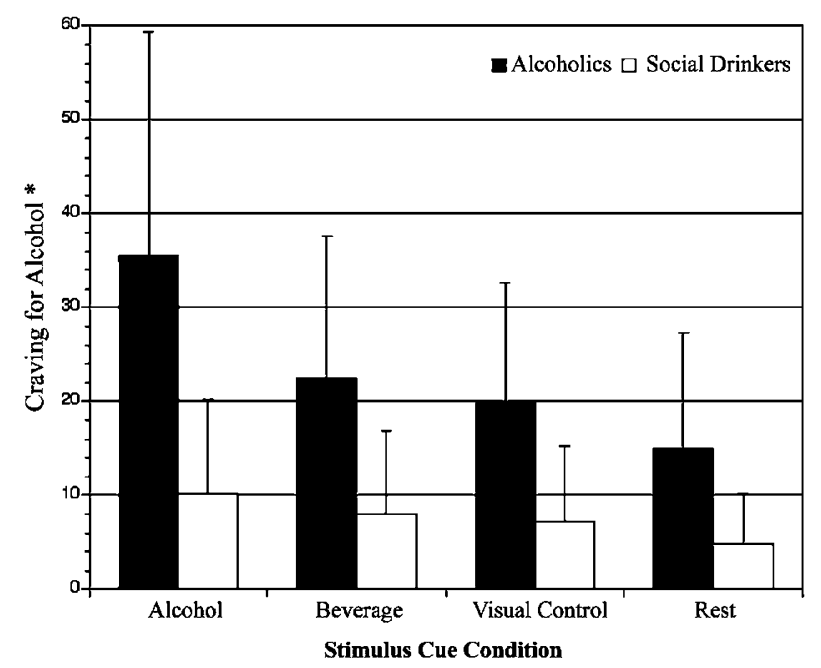

Figure 2 Craving ratings within the MRI scanner. The mean subjective rating for 'desire to consume alcohol' revealed a significant between-subject effect $F=10.712, d f=1, p=0.004$ and within-subject effect (seen only in the alcohol group) $\mathrm{F}=10.283, \mathrm{df}=\mathrm{I}, \mathrm{p}=0.005$. ${ }^{*}$ Craving was rated on an analog scale (range $0-100$ ).

cues are summarized in Table 2 and depicted in Figure 3. The results of this comparison were the most salient and robust effect in our original study (George et al, 2001). Confirming our earlier work, the alcoholics, and not the social drinkers, had robust activation in prefrontal and limbic regions. In contrast to our earlier study, the social drinker group had some activation (cingulate) during this comparison. Additionally, the regions activated in the alcoholics were not exactly the same ones as in our earlier study (see discussion).

\section{Comparison of Alcohol Cues with Control Cues}

The brain areas significantly activated during the comparison of alcohol cues with control cues are summarized in Table 2. Three brain areas that were activated in the alcoholic group during the comparison of alcohol cues with beverage cues remained activated in this comparison: anterior cingulate, right insula, and left insula.

\section{Comparison of Beverage Cues with Control Cues}

As summarized in Table 2, the comparison of beverage cues with control cues resulted in very few areas of activation. The alcoholic group contained activation in the left hippocampus, whereas the social drinkers had both left and right occipital activation.

\section{Comparison of Visual Control Cues with Rest Control}

The comparison of visual control and rest control pictures is important within each group as it serves as an internal control to verify that regional brain activation occurs, and that within-group differences in activation are due to the specific contrasts and are not influenced by inattention, movement, or lingering toxic or metabolic effects of alcohol or blood flow. As such, one would expect to find occipital activation in this comparison due to the various colors in 
Alcohol fMRI

$\mathrm{H}$ Myrick et al

Table 2 Brain Areas Activated in Alcoholics

Talairach coordinates

Region

Side

$x$

$Y$

Z

$\operatorname{Max} Z$

\# Voxels

Alcohol-beverage comparison

Alcoholics

Right Insula

Cingulate

Nucleus accumbens

Nucleus accumbens

Left insula

Ventral tegmental area

Social drinkers

Posterior cingulate

Anterior cingulate

Alcohol-control comparison

Alcoholics

Anterior cingulate
Globus pallidus
Insula
Lateral orbital cortex
Hippocampus
Posterior cingulate
Insula
Hippocampus
Superior frontal

Social drinkers

Hippocampus

Superior frontal cortex

Anterior cingulate

Middle frontal cortex

Hippocampus

Middle frontal cortex

Beverage-control comparison

\section{Alcoholics}

Hippocampus

Left

Right
Left
Left
Left
Left
Right

28

$-9$

$-2$

$-42$

$-23$

40

$-3$

$-19$

34

34

3.44

2.38

52

39

Social drinkers

$\begin{array}{llrrrrr}\text { Occipital cortex } & \text { Left } & -16 & -104 & -8 & 6.58 & 126 \\ \text { Occipital cortex } & \text { Right } & 16 & -104 & -4 & 5.44 & 172\end{array}$

\section{Craving rating and brain activity correlation during alcohol condition}

\section{Alcoholics}

\begin{tabular}{llrrrrr} 
Nucleus accumbens & Left & -10 & 14 & -7 & 3.46 & 2.98 \\
Anterior cingulated & Left & -7 & 42 & 2 & 12 \\
Orbital frontal cortex & Left & -17 & 20 & -16 & 3.67 \\
\hline
\end{tabular}

Within-subject comparisons of alcohol-beverage condition, alcohol-control condition, beverage-control condition, and correlation with real-time analog craving ratings in alcohol subjects $(n=10)$. The Talairach coordinates for the peak voxel are listed. The cluster statistical weight is $p<0.05$ corrected (there was only one significant cluster per region listed). 
the visual control compared to the black crosshair and white background of the rest condition. Accordingly, within-group analyses found that both the alcoholic group and social drinkers showed areas of significant activation while viewing the visual control images compared to the rest (crosshair) control in the occipital lobes. Importantly, there was no statistical difference in the number of voxels activated in the occipital lobe between the alcoholic group and social drinkers $(t=-0.77, \mathrm{df}=9, \quad p=0.46)$. This internal control demonstrates that there is little, if any, difference in nonspecific brain activation within the two groups due to differential attention, movement, or the lingering toxic effects of alcohol or other reasons.

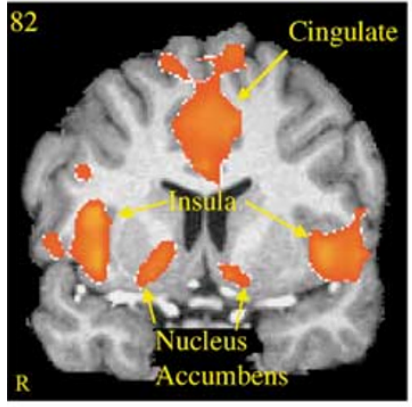

Alcoholics $(n=10)$

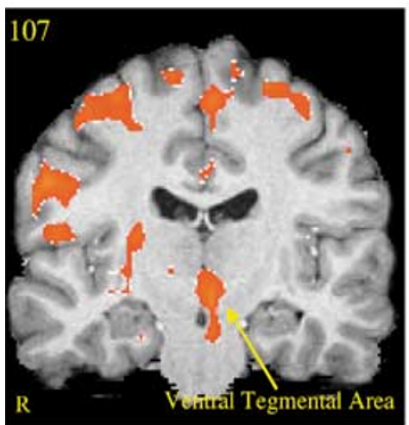

Alcoholics $(\mathrm{n}=10)$

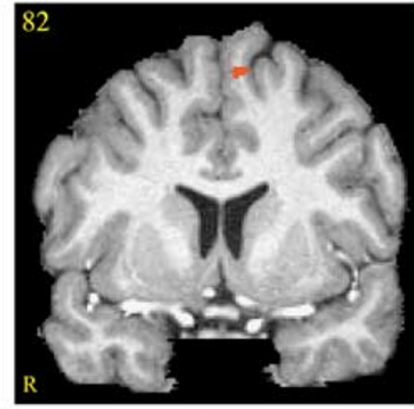

Controls $(\mathrm{n}=10)$

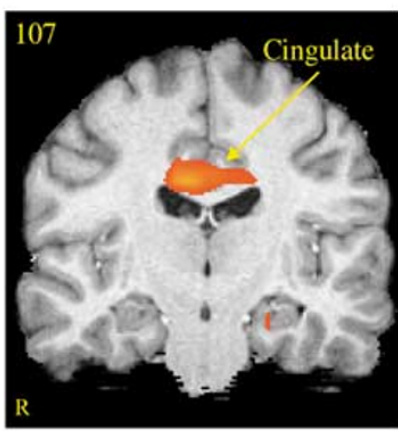

Controls $(\mathrm{n}=10)$
Figure 3 Brain areas activated during alcohol-beverage comparison Brain regions with significantly increased activation in one task (alcohol) compared with another (beverage) are depicted in color on representative coronal structural magnetic resonance imaging scans. The threshold for determining significance is an extent cluster threshold of $p<0.05$.

\section{Temporal Correlation of Craving Data with Brain Activity}

As can be seen in Figure 4, in the alcohol group, the correlation of the craving data obtained at the end of each alcohol condition with regional brain activity measured during viewing of alcohol pictures revealed activation in the left nucleus accumbens, anterior cingulate as well as the left orbitofrontal cortex $(n=10, z=1.96)$. In contrast, the correlation between craving data obtained at the end of each beverage condition and brain activity measured during the viewing of nonalcoholic beverages showed no regions of significant correlation. Importantly, there was no significant correlation between craving measures and brain activity in the alcohol or beverage condition in the social drinkers.

\section{Between-Group Results}

There was no statistically significant between-group difference in brain activation between the alcoholics and social drinkers at the level of $z=1.645$ for any of the comparisons (Alc-Bev, Alc-Rest, Control-Rest).

\section{DISCUSSION}

These results provide further evidence that alcohol cueinduced brain activity can be elicited in alcoholics within the fMRI scanner during the presentation of taste and visual alcohol cues. Nontreatment-seeking alcoholics self-rated significantly higher 'real-time' alcohol craving ratings and differentially activated limbic and cortical brain regions as compared to control subjects. Specifically, after a sip of alcohol, the alcohol subjects had activation in the nucleus accumbens (bilateral), ventral tegmental area, insula (bilateral), and anterior cingulate while viewing alcohol cues compared to viewing the beverage cues. In contrast, on this alcohol-specific contrast, social drinkers only had slight activation in the cingulate gyrus. In addition, within the alcohol group alone, real-time craving ratings while in the MRI scanner correlated with activation in the left nucleus accumbens, anterior cingulate as well as in the left orbitofrontal cortex.

The brain regions found activated in the current study are consistent with other published neuroimaging cue stimulation studies involving cocaine, opiates, nicotine, or alcohol. In particular, regions activated include both limbic and

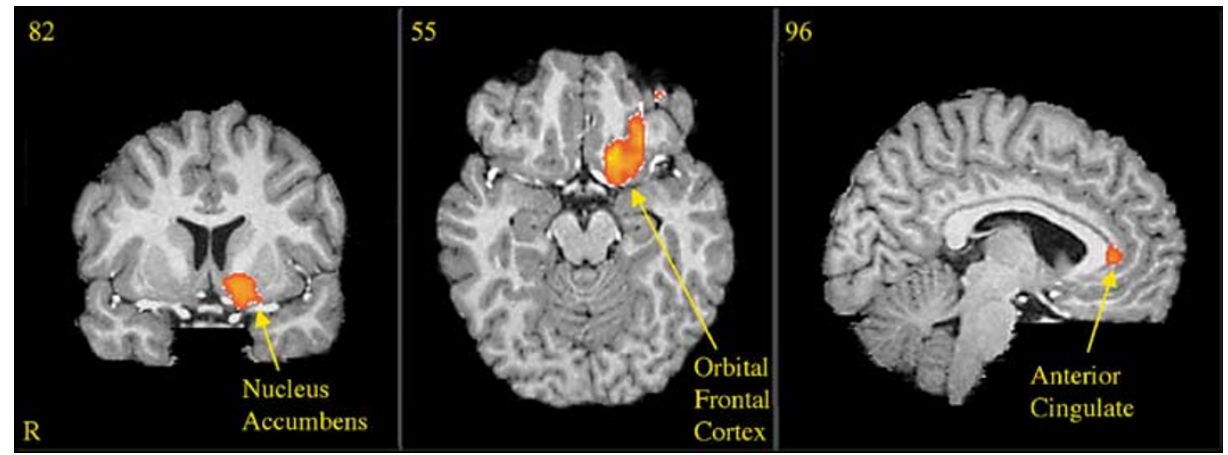

Figure 4 Correlation of subjective ratings with brain activity. Brain regions with a significant positive correlation with analog craving ratings are depicted in color on representative structural magnetic resonance imaging scans. The threshold for determining significance is an extent cluster threshold of $p<0.05$ 
cortical areas, while there is not complete overlap of all brain regions activated across all cue-induced craving studies, several brain regions show consistent activation. These include various portions of the cingulate gyrus (Breiter et al, 1997; Childress et al, 1999; Garavan et al, 2000; Grant et al, 1996; Kilts et al, 2001; Mass et al, 1998; Wexler et al, 2001; Brody et al, 2002), the orbital cortex (Grant et al, 1996; Mass et al, 1998; Wang et al, 1999), the nucleus accumbens (Breiter et al, 1997; George et al, 2001; Kilts et al, 2001), and the insula (Breiter et al, 1997; Wang et al, 1999).

The nucleus accumbens and ventral tegmental area have received considerable attention as neural substrates mediating addiction (Pointieri et al, 1995; Koob and Le Moal, 1997). Both regions have been implicated in the rewarding properties of reinforcing behaviors and substances, and have extensive cortical and subcortical connections. In animals, dopaminergic projections from the ventral tegmental area to the nucleus accumbens fire in response to presentation of reward cues and reward anticipation (Berridge and Robinson, 1998; Ikemoto and Panksepp, 1999; Schultz et al, 1992). A recent fMRI study in humans found that anticipation of increasing monetary rewards in healthy volunteers yielded increasing nucleus accumbens activation (Knutson et al, 2001).

As noted above, different subregions of the cingulate gyrus have been activated in several cocaine cue-induction paradigms. The cingulate is involved in assessing the salience of emotional and motivational information (Bush et al, 2000). As such, it may play a role in linking environmental cues with the emotional states associated with substance use and therefore be involved with craving and the addictive process. Therefore, activation of the cingulate might be expected if subjects linked the alcohol cues with positive expectations of alcohol use. It has been reported that anterior cingulate activation may be related to the expectancy of reward and in our situation, expectancy to consume alcohol (Shidara and Richmond, 2002).

The insula is considered a part of the limbic system. The insula receives input from the basolateral amygdala (Krettek and Price, 1977; Shinonaga et al, 1994) and projects to the striatum (Wright and Groenewegan, 1996) and is thus is considered an integral part of the corticomesolimbic system. The insula is hypothesized to mediate higher cognitive processes such as memory and learning related to taste (Balleine and Dickinson, 2000; Braun et al, 1972; Kiefer and Braun, 1977). Lesion studies support the hypothesis that insular cortex is crucial to encoding the incentive value of taste during instrumental conditioning (Balleine and Dickinson, 2000). Recent studies suggest that activation of the insular cortex is also correlated with drugrelated behavior. Insular activation has been found in a cocaine theme interview (Wang et al, 1999), with presentation of cocaine-related cues (Bonson et al, 2002), and during cocaine administration (Breiter et al, 1997). The work by Breiter et al (1997) is especially interesting given that both nucleus accumbens and insula activation was found. Sell et al (2000) found that craving during heroin-related visual cue stimulation correlated with left insula activity as well as orbitofrontal cortex activity. Likewise, a recent study by Brody et al (2002) found that the increased craving for cigarettes while watching a videotape of cigarette-related cues correlated with anterior insula activation bilaterally as well as the orbitofrontal cortex. These results are consistent with the results reported here for alcohol cue stimulation.

The left orbitofrontal cortex, left nucleus accumbens, and anterior cingulate, were found to correlate with the craving data obtained while subjects were in the scanner. While activity in the nucleus accumbens and anterior cingulate was found in the alcohol minus beverage condition, the orbitofrontal cortex activity appeared only in the correlation with craving ratings. Orbitofrontal cortex activity has been found in several neuroimaging studies involving cocaine-related cues (Grant et al, 1996; Wang et al, 1999). The orbitofrontal cortex is involved in processing information about reinforcing and aversive stimuli and has extensive connections with the subcortical limbic structures (Haber et al, 1995; Zald and Kim, 1996). Orbitofrontal cortex lesions have been found to disrupt inhibitory and emotional mechanisms resulting in impulsive and socially inappropriate behavior (Anderson et al, 1999; Bechara et al, 1994). In addition, overactivation of the orbitofrontal cortex has been associated with obsessivecompulsive behaviors (Heinz, 1999). Therefore, dysfunction in the orbitofrontal cortex can lead to impaired inhibitory control and may be responsible for continued substance use despite obvious impairment (Volkow and Fowler, 2000; London et al, 2000).

While our most salient a priori hypothesis centered on the comparison of alcohol cues to beverage cues, other comparisons were analyzed. The comparison of alcohol cues with control cues yielded only three areas of activation that were similar to the comparison of alcohol cues to beverage cues: anterior cingulate, left insula, and right insula. These areas of activation were not found in the comparison of beverage cues to control cues. The finding of different areas of activation in the comparison of alcohol cues to control cues is of no great surprise. In the comparison of alcohol cues to beverage cues, the only salient difference between the cues is that one of the 'beverages' contains alcohol. In the comparison of alcohol cues to control cues, there are major differences in the salience. The control pictures consist of the alcohol and beverage pictures that have been blurred, so that the object cannot be recognized, but retains the same hue and color. The resulting control cues may offer somewhat of a novel stimulus. Perhaps, this accounts for the hippocampal activation in the comparisons of both alcohol cues to control cues as well as beverage cues to control cues.

Modell et al (1990) developed a model of craving for alcohol based on the similarity of the compulsions associated with obsessive-compulsive disorder (OCD) and the desire to drink described by alcoholics. Investigators have noted that some aspects of craving resemble obsessive and compulsive phenomenon (Anton et al, 1995; Anton, 1999; Modell et al, 1990), including both urges and the inability to resist these urges. Dysfunction in a circuit involving the striato-thalamocortical loop may underlie this poor control of urges to drink (Anton et al, 1995; Volkow and Fowler, 2000). As such, dysfunction in the orbitofrontal cortex might be involved in craving for alcohol, much like it is in OCD. In the current study, it is not clear whether the 
activation in the orbital frontal areas is consistent with a positive expectation of reward (craving) or an attempt by the subjects to resist this craving during confinement to the scanner where drinking was impossible. Future research may attempt to further characterize the dimensions of the craving experience that are related to these brain activations.

The lack of consistency in areas of regional brain activity in studies evaluating craving in alcoholics is worthy of discussion. This inconsistency is not only due to the different imaging techniques employed but also the specific alcohol cues utilized and patient population studied. In reference to the specific alcohol cues used to illicit 'craving', it is possible that visual presentation alone may not provide the salience necessary to induce alcohol craving (Anton and Drobes, 1998). A priming 'sip' of alcohol as used in Modell and Mountz (1995) and George et al (2001), and the current study may provide a more salient or powerful cue to illicit alcohol craving. Data generated from nonimaging clinical lab studies have indicated that a taste prime can increase craving (de Wit, 2000; O'Malley et al, 2002). The length of abstinence among the studies could also lead to the differences in the induced regional activation. As the length of abstinence increases, it is likely that craving decreases. In addition, patients with longer periods of abstinence may have greater resistance to craving than actively drinking subjects. Therefore, the presentation of alcohol cues to the nontreatment-seeking alcoholdependent subjects in the current study may have had greater salience than subjects with longer periods of abstinence. Future studies might repeatedly image individuals overtime, such as during the initiation of abstinence, during maintained abstinence, and immediate after relapse drinking to further address these issues. The evaluation of regional brain activation to craving during each of these times could elucidate and provide a more complete picture of the 'addicted brain'.

The fact that the current findings differ from our initial study by George et al (2001) warrants further discussion. The purpose of the original study was to evaluate the ability to perform alcohol cue-stimulation in the fMRI scanner and to ascertain whether alcoholics would experience craving while in such an unnatural environment. It was positive on both accounts. The study revealed that alcohol subjects exposed to alcohol cues had increased brain activity in the prefrontal cortex and anterior thalamus. There are several reasons why we did not exactly replicate those initial results. First, due to technology constraints, the original work only imaged the anterior third of the brain while the current study utilized whole brain imaging. Second, the original study used prism glasses for the subjects to view images that were projected onto a screen located at their feet while lying on the scanner gantry. The current study used 3-D, MRIcompatible video goggles that offered increased resolution, greater subject comfort, and likely caused less perceptual distraction. Third, the original study was completed on a Picker Edge $1.5 \mathrm{~T}$ system, while the current study was completed on a Philips $1.5 \mathrm{~T}$ system. Fourth, the statistical analysis of those images was slightly different, using earlier versions of image data analysis software. Based on the improvement in image data analysis software, our analysis techniques differ between the studies. In the prior study, we only generated regional brain 'activation' maps for the condition of interest (ie alcohol minus beverage condition). Our current data analysis techniques allow for us to evaluate 'deactivation' maps (ie beverage minus alcohol condition) in addition to the 'activation' maps for the condition of interest. The combination of the activation and deactivation maps (alcohol minus beverage and beverage minus alcohol) generates more of an 'absolute' value of regional brain activity. Finally, the original study relied on retrospective (postimaging) ratings of craving for alcohol. The current study used 'real-time' ratings of craving while the subjects were in the scanner. The differences in brain regions scanned, image quality, image power, and use of real-time ratings, make the current study not a formal direct replication of our previous work but probably more meaningful. Importantly, both studies found differences between alcoholics and social drinkers only during the alcohol-specific contrast. Moreover, both studies found increased prefrontal brain activity in the alcoholics during the alcohol-specific cue induction.

There are several limitations of the current study. First, the study has a small sample size of only 10 subjects per group. However, the imaging literature is generally based on studies with equivalent sample sizes. As well, these two groups are well matched on many important variables such as age, gender, and handedness. Second, two alcohol subjects and seven social drinkers were excluded from data analysis due to excessive movement during the scanning session that was unable to be corrected $(>1 \mathrm{~mm})$. Third, while we were able to find significant within-group effects, we were unable to find between-group differences in brain activity. This, again, is most likely due to the small sample size of the study and variability in the data.

In summary, craving for alcohol represents a significant trigger to relapse to alcohol use in many alcoholics. Exposure to environmental stimuli associated with drinking (such as pictures, smells, and places of ingestion) can strongly stimulate the 'urge' or desire to consume alcohol in alcohol-dependent individuals. In this context, craving for alcohol can be thought of as a useful target for both counseling and pharmacotherapies aimed at reducing alcoholism (Anton, 1999; Flannery et al, 2001; Jaffe et al, 1996). While it appears that craving is accompanied by changes in regional brain activity, what changes and what structures are most sensitive to cue-induced craving are beginning to be clearly elucidated. Identifying the brain regions involved with craving may lead to better interventions which in turn will improve the treatment success of alcoholics.

\section{ACKNOWLEDGEMENTS}

This work was funded by the Charleston Alcohol Research Center (ARC) (NIAAA 2 P50 AA10761-03). Dr Myrick is also funded through NIAAA K23 AA00314 and the VA Research and Development Service, Ralph H Johnson Department of Veterans Affairs Medical Center. There are no conflicts of interest, financial or otherwise, between any of the authors and any other person or entity that might bias the results of this study. 


\section{REFERENCES}

Anderson SW, Bechara A, Damasio H, Tranel D, Damasio AR (1999). Impairment of social and moral behavior related to early damage in human prefrontal cortex. Nat Neurosci 11: 1032-1037.

Anton RF (1999). What is craving? Models and implications for treatment. Alcohol Res Health 23: 165-173.

Anton RF, Drobes DJ (1998). Clinical measurement of craving in addiction. Psych Annals 28: 553-560.

Anton RF, Moak DH, Latham P. (1995). The obsessive compulsive drinking scale: a self-rated instrument for the quantification of thoughts about alcohol and drinking behavior. Alcoholism: Clin Exp Res 19: 92-99.

Anton RF, Moak DH, Latham PK (1996). The obsessive compulsive drinking scale. A new method of assessing outcome in alcoholism treatment studies. Arch Gen Psychiatry 53: 225-231.

Balleine BW, Dickinson A (2000). The effect of lesions of the insular cortex on instrumental conditioning: evidence for a role in incentive memory. J Neurosci 20: 8954-8964.

Bechara A, Damasio AR, Damasio H, Anderson SW (1994). Insensitivity to future consequences following damage to human prefrontal cortex. Cognition 50: 7-12.

Berridge KC, Robinson TE (1998). What is the role of dopamine in reward: hedonic impact, reward learning, or incentive salience? Brain Res Brain Res Rev 28: 309-369.

Bonson KR, Grant SJ, Contoreggi CS, Links JM, Metcalfe J, Weyl HL et al (2002). Neural systems and cue-induced cocaine craving. Neuropsychopharmacology 26: 376-386.

Braun JJ, Slick TB, Lorden JF (1972). Involvement of gustatory neocortex in the learning of taste aversions. Physiol Behav 9: 637-641.

Braus DF, Wrase J, Grusser S, Hermann D, Ruf M, Flor H et al (2001). Alcohol-associated stimuli activate the ventral striatum in abstinent alcoholics. J Neural Transmission 108: 887-894.

Breiner MJ, Stritzke WGK, Lang AR, Patrick CJ (1995). The Normative Appetitive Picture System [Photographic Slides]. Florida State University: Tallahassee.

Breiter HC, Gollub RL, Weisskoff RM, Kennedy DN, Makris N, Berke JD, Goodman JM et al (1997). Acute effects of cocaine on human brain activity and emotion. Neuron 19: 591-611.

Brody AL, Mandelkern MA, London ED, Childress AR, Lee GS, Bota RG et al (2002). Brain metabolic changes during cigarette craving. Arch Gen Psych 59: 1162-1172.

Bush G, Luu P, Posner MI (2000). Cognitive and emotional influences in anterior cingulate cortex. Trends Cognitive Sci 4: $215-222$.

Childress AR, Mozley PD, McElgin W, Fitzgerald J (1999). Limbic activation during cue-induced cocaine craving. Am J Psychiatry 156: $11-18$.

CSEA-NIMH (1995). The International Affective Picture System [Photographic Slides]. University of Florida: Gainesville.

De Wit H (2000). Laboratory-based assessment of alcohol craving in social drinkers. Addiction 95: S165-S169.

Flannery BA, Roberts AJ, Cooney N, Swift RM, Anton RF, Rohsenow DJ (2001). The role of craving in alcohol use, dependence, and treatment. Alcohol Clin Exp Res 25: 299-308.

Garavan H, Pankiewicz J, Bloom A, Cho JK, Sperry L, Ross TJ et al (2000). Cue-induced cocaine craving: neuroanatomical specificity for drug users and drug stimuli. Am J Psychiatry 157: 1789-1798.

George MS, Anton RF, Bloomer C, Teneback C, Drobes DJ, Lorberbaum JP et al (2001). Activation of prefrontal cortex and anterior thalamus in alcoholic subjects on exposure to alcoholspecific cues. Arch Gen Psychiatry 58: 345-352.

Grant S, London ED, Newlin DB, Villemagne VL, Liu X, Contoreggi $C$ et al (1996). Activation of memory circuits during cue-elicited cocaine craving. Proc Natl Acad Sci USA 93: 12040-12045.
Haber SN, Kunishio K, Mizobuchi M, Lynd-Balta E (1995). The orbital and medical prefrontal circuit through the primate basal ganglia. J Neurosci 15: 4851-4867.

Heinz A (1999). Neurobiological and anthropological aspects of compulsions and rituals. Pharmacopsychiatry 32: 223-229.

Hommer D, Andreasen P, Rio D, Williams W, Ruttimann U, Momenan R et al (1997). Effects of $m$-chlorophenylpiperazine on regional brain glucose utilization: a positron emission tomographic comparison of alcoholic and control subjects. J Neurosci 17: 2796-2806.

Ikemoto S, Panksepp J (1999). The role of nucleus accumbens dopamine in motivated behavior: a unifying interpretation with special reference to reward-seeking. Brain Res Brain Res Rev 31: 6-41.

Jaffe AJ, Rounsaville B, Chang G, Schottenfield RS, Meyer RE, O'Malley SS (1996). Naltrexone, relapse prevention, and supportive therapy with alcoholics: an analysis of patient treatment matching. J Consult Clin Psychol 64: 1044-1053.

Kiefer SW, Braun JJ (1977). Absence of differential associative responses to novel and familiar taste stimuli in rats lacking gustatory neocortex. J Comp Physiol Psychol 91: 498-507.

Kilts CD, Schweitzer JB, Quinn CK, Gross RE, Faber TL, Muhammad F et al (2001). Neural activity related to drug craving in cocaine addiction. Arch Gen Psychiatry 58: 334-341.

Knutson B, Adams CM, Fong GW, Hommer D (2001). Anticipation of increasing monetary reward selectively recruits nucleus accumbens. J Neurosci 21: RC159.

Koob GF, Le Moal M (1997). Drug abuse: hedonic hemostatic dysregulation. Science 278: 52-58.

Krettek JE, Price JL (1977). Projections from the amygdaloid complex and adjacent olfactory structures to the entorhinal cortex and to the subiculum in the rat and cat. J Comp Neurol 172: 723-752.

London ED, Ernst M, Grant S, Bonson K, Weinstein A (2000). Orbitofrontal cortex and human drug abuse: functional imaging. Cerebral Cortex 10: 334-342.

Mass LC, Lukas SE, Kaufman MJ, Weiss RD, Daniels SL, Rodgers VW et al (1998). Functional magnetic resonance imaging of human brain activation during cue-induced cocaine craving. Am J Psychiatry 155: 124-126.

Modell JG, Mountz JM (1995). Focal cerebral blood flow change during craving for alcohol measured by SPECT. J Neuropsychol 7: $15-22$.

Modell JG, Mountz JM, Beresford TP (1990). Basal ganglia/limbic striatal and thalamocortical involvement in craving and loss of control in alcoholism. J Neuropsychiatry Clin Neurosci 2: $123-144$.

O’Malley SS, Krishnan-Sarin S, Farren C, Sinha R, Kreek J (2002). Naltrexone decreases craving and alcohol self-administration in alcohol-dependent subjects and activates the hypothalamopituitary-adrenocortical axis. Psychopharmacology (Berlin) 160: 19-29.

Pointieri F, Tanda G, Di Chiara G (1995). Intravenous cocaine, morphine, and amphetamine preferentially increased extracellular dopamine in the 'shell' as compared with the 'core' of the rat nucleus accumbens. Proc Natl Acad Sci USA 92: 12304-12308.

Schneider F, Habel U, Wagner M, Franke P, Salloum JB, Shah NJ et al (2001). Subcortical correlates of craving in recently abstinent alcoholic patients. Am J Psychiatry 158: 1075-1083.

Schultz W, Appicella P, Scarnati E, Ljungber T (1992). Neuronal activity in monkey ventral striatum related to the expectation of reward. J Neurosci 12: 4595-4610.

Sell LA, Morris JS, Bearn J, Frackowiak RS, Friston KJ, Dolan RJ (2000). Neural response associated with cue evoked emotional states and heroin in opiate addicts. Drug Alcohol Dependence 60: 207-216. 
Shidara M, Richmond BJ (2002). Anterior cingulate: single neuronal signals related to degree of reward expectany. Science 296: 1709-1711.

Shinonaga Y, Takada M, Mizuno N (1994). Topographic organization of collateral projections from the basolateral amygdaloid nucleus to both the prefrontal cortex and nucleus accumbens in the rat. Neuroscience 58: 389-397.

Sobell LC, Sobell MB, Leo GI, Cancilla A (1988). Reliability of a timeline method: assessing normal drinkers' reports of recent drinking and a comparative evaluative across several populations. Br J Addict 83: 393-402.

Sullivan JT, Sykora K, Schneiderman J, Naranjo CA, Sellers EM (1989). Assessment of alcohol withdrawal: the revised Clinical Institute Withdrawal Assessment for Alcohol Scale (CIWA-Ar). Br J Addict 84: 1353-1357.

Talairach J, Tournoux P (1988). Co-planar Stereotaxic Atlas of the Human Brain: 3-Dimensional Proportional System: An Approach to Cerebral Imaging. Thieme-Stratton, Inc.: New York.

Volkow N, Fowler J (2000). Addiction, a disease of compulsion and drive: involvement of the orbitofrontal cortex. Cereb Cortex 10: 318-325.

Wang GJ, Volkow ND, Fowler JS, Cervany P, Hitzemann RJ, Pappas NR et al (1999). Regional brain metabolic activation during craving elicited by recall of previous drug experiences. Life Sci 64: 775-784.

Wexler BE, Gottschalk CH, Fulbright RK, Prohovnik I, Lacadie CM, Rounsaville BJ et al (2001). Functional magnetic resonance imaging of cocaine craving. Am J Psychiatry 158: 86-95.

Woods RP, Cherry SR, Mazziotta JC (1992). Rapid automated algorithm for aligning and reslicing PET images. J Comput Assist Tomogr 16: 620-633.

Wright CI, Groenewegan HJ (1996). Patterns of overlap and segregation between insular cortical, intermediodorsal thalamic and basal amygdaloid afferents in the nucleus accumbens of the rat. Neuroscience 73: 359-373.

Zald DH, Kim SW (1996). The anatomy and function of the orbitofrontal cortex. I: Anatomy, neurocircuitry, and obsessivecompulsive disorder. J Neuropsychiatry Clin Neurosci 8: 125-138. 